\title{
Characterization of a sustainable mortar based on mineral additions and prepared sand
}

\author{
Khemissi Bellalmi ${ }^{1}$, Larbi Belagraa ${ }^{2,3^{*}}$, Bachir Taallah ${ }^{1}$, Nassima Bakir $^{2}$ and Lila Briki ${ }^{2}$ \\ ${ }^{1}$ Department of civil engineering, faculty of sciences and technology, Mohammed Khider university, Biskra (7000), Algeria. \\ ${ }^{2}$ Department of civil engineering, Faculty of Technology, Med Boudiaf University of M'sila , (28.000), Algeria.. \\ ${ }^{3}$ Laboratory of Materials and Electronic Systems (LMSE), faculty of sciences and technology, Mohammed el Bachir el Ibrahimi \\ university, BordjBouArreridj(34000), Algeria.
}

\begin{abstract}
The present study is to investigate the physical and mechanical properties of the prepared sand mortars, mainly based on the local Oued Souf sand region south of Algeria, this in accordance with standard sand grading. The principal aim of the research is to replace the restricted fine part between $(0.08$ and 0.16 $\mathrm{mm}$ ) which is of the order $15 \%$ and to substitute it with additions active slag (S) and inert glass powder(GP) with dosages of 5, 10 and $15 \%$ and maintain the rest of the granular fractions of the sand studied fixed. Thus, to see and analyze the influence of these additions on the physical properties and in regards the mechanical performances of confected prepared sand mortars. The results showed the advantageous effect of replacing the said prepared sand with two additions (slag and glass powder) on physical, mechanical properties mortars based on this local sand by improving the performance of these cement products, especially at an optimal percentage of $10 \%$.
\end{abstract}

\section{Nomenclature}

-MT, is the control mortar mixture without addition( $15 \%$ Qtz).

-MS5, is the mortar with $5 \%$ slag replacement.

-MS10, is the mortar with $10 \%$ slag replacement.

-MS15, is the mortar with $15 \%$ slag replacement.

-MC1, is the combined mortar at $10 \%$ replacement ( $5 \% \mathrm{~S}+5 \% \mathrm{GP})$

$\bullet \mathrm{MC} 2$, is the combined mortar at $15 \%$ replacement $(7.5 \% \mathrm{~S}+7.5 \% \mathrm{GP})$

\section{Introduction}

Now days, the improvements of qualities of cementitious materials still of a great interest as the subject of several scientific research dealing with parameters that can influence the performances of concrete and mortars. This could explain the major concern given for the activation of binder itself with a cement matrix improved performances [1], [2].

These novel construction materials under certain conditions have lower greenhouse gas emissions, environmental impacts and $\mathrm{CO}_{2}$ emission associated with their manufacture [3], [4]. In the literature, most of the studies of alkali activated materials (AAMs) are bound to the use of only a few precursor materials such as blast furnace slag [5-9], metakaolin [10,11] and fly ash $[12,13]$.

However. the use of the active additions in the granulometric composition of a quartz sand can grant it a character of an active material which can participate positively in the process of hydration and improved the different characteristic of cement materials whose are related exclusively to the enhancement of the mechanical responses $[1,14]$. It is worth to mention that a lack of previous works on the subject dealing with activated sand in bibliographical sources matters presented a real handicap in dressing a deep literature review for the moment.

The study undertaken in this work aims to achieve the following main objectives. Principally, the first aim is to see the effect of the incorporation of mineral additions [active $\operatorname{slag}(\mathrm{S})$ and inert glass powder (GP)] on the physico-mechanical properties of mortars made from local standardized sand prepared in the laboratory of the civil engineering department. The fine fraction of 0.08 to $0.16 \mathrm{~mm}$ has been replaced by a mineral addition (slag and glass powder) at a replacement rates for slag of 5, 10 and 15\%. Further, combined blended mortars [Slag (S) and Glass Powder (GP)] up to a percentage of $15 \%$ were the subject of this investigation. The experimental protocol covers the set of properties, density as well as mechanical responses.

\section{Experimental work}

\subsection{Materials}

\subsubsection{Cement}

Portland cement CEM I 42.5 NSR3; conforming to the standard (EN - 196, 1) was used. Which is a gray

\footnotetext{
* Corresponding author: larbi.belagraa@univ-msila.dz
} 
sulfate-resistant cement resulting of milling a clinker containing a low level of calcium aluminates with a $\mathrm{C} 3 \mathrm{~A}$ level $<3 \%$ and a proportion of gypsum less than that of a Portland cement composite. According to the European standard (EN 197-1) [15]. The properties of cement used are reported in table 1 .

Table 1. Properties of used cement CEM I 42.5N-SR3.

\begin{tabular}{|c|c|}
\hline \multicolumn{2}{|c|}{ Chemical composition of cement } \\
\hline L O I $(\%)$ & $0.5-3$ \\
\hline $\left.\mathrm{SO}_{3}\right)(\%)$ & $1.8-3$ \\
\hline $\mathrm{MgO}(\%)$ & $1.2-3$ \\
\hline Chlore (\%) & $0.01-0.05$ \\
\hline \multicolumn{2}{|c|}{ Physical properties of cement. } \\
\hline Consistancy $(\%)$ & $25 a ̀ 28$ \\
\hline Fineness $\left(\mathrm{cm}^{2} / \mathrm{g}\right)$ & 3200à3800 \\
\hline Shrinkage at 28 days $(\mu \mathrm{m} / \mathrm{m})$ & $<1000$ \\
\hline Expansion $(\mathrm{mm})$ & $\leq 2.0$ \\
\hline Heat of hydratation & $<270 \mathrm{j} / \mathrm{g}$ \\
\hline
\end{tabular}

\subsubsection{Sand}

The sand used during this experimental action is a desert sand from the Oued Souf region (South-east of Algeria), which has an equivalent sand modulus before washing equal to 81.80 and a fineness modulus in the order of 2.41 , which shows the good quality of this natural sand, the activated sand subject to the preparation is made following the steps;

Firstly, washing is carried out by the continuous use of hot water two or three times, to avoid the presence of all the harmful elements (presence of some very fine particles of white color). Then a drying is done in the open air. After that a sieving operation in a clean and dry sieve column series of 2.0, 1.6, 1.00, 0.5, 0.16, $0.08 \mathrm{~mm}$ is performed. The fractions of the quartz were mixed and packed in bags of $1350 \mathrm{~g} \pm 5 \mathrm{~g}$, which will be used for the preparation of the mortar mixtures later on. The prepared sand.is appreciated for its good characteristics and prepared for such use in the Laboratory of Civil Engineering department of Mohamed Boudiaf University of M'sila. The sand must have rational proportions of grains of different dimensions so that they have a minimum porosity $[1,9,16]$.

\subsubsection{Additions}

Granulated slag addition is widely used as a substitute for Portland cement in concrete to improve the mechanical and durability properties of concrete and to bring economic and environmental benefits. The use of slag has advantages due to their excellent hydraulic properties compared to ordinary Portland cement, but also disadvantages linked to the low initial resistance, which have limited its use. Several studies have been carried out in order to improve the reactivity of the slag.

In our study we used the granulated blast furnace slag from the steel plant of El-Hadjar, of Annaba region, the chemical composition was determined by the X-ray Fluorescence Spectrometry test at the Lafarge laboratory is indicated in the table 2 [17], [18]. For The Glass powder (GP) used, the chemical composition and the physical characteristic depends on the nature of the glass, its color and its hardness, but in the majority of cases, the essential elements about its properties are reported in table $2[17,19,20]$.

\subsubsection{Mixing water}

The mixing tap water supplied and available at the laboratory of the department was used for studied mixtures.

\subsection{Mortar Preparation}

The sets of mortar obtained are related respectively to the proportions of the additions used in each mix. The mortar specimens adopted the following proportions $1 / 4$ cement, $3 / 4$ sand and water cement ratio w/c equals to 0.5 . Prismatic specimens of dimensions $(40 \mathrm{x} 40 \mathrm{x}$ 160) $\mathrm{mm}^{3}$ were used. After twenty four hours, specimens were demolded and cured in the water until the due age of testing 7, 14 and 28 dqys, weighted before the flexural and compressive strengths tests undertaken..

Table 2. Properties of slag(S) and glass powder (GP) addition.

\begin{tabular}{|c|c|c|c|c|c|c|c|}
\hline \multicolumn{8}{|c|}{ Chemical composition of slag and glass powder } \\
\hline $\begin{array}{c}\text { Eleme } \\
\text { nt } \\
\%\end{array}$ & $\mathrm{SiO}_{2}$ & $\mathrm{Na}_{2} \mathrm{O}$ & $\mathrm{CaO}$ & $\mathrm{SO}_{3}$ & $\mathrm{~K}_{2} \mathrm{O}$ & $\mathrm{Al}_{2} \mathrm{O}_{3}$ & $\begin{array}{l}\text { Oxyde } \\
\text { (SbO) }\end{array}$ \\
\hline$(\mathrm{S})$ & 39.48 & - & 41 & 1.5 & 0.4 & 4.2 & $\S$ \\
\hline (GP) & $\begin{array}{c}68- \\
74\end{array}$ & $\begin{array}{l}12- \\
16\end{array}$ & $\begin{array}{l}7- \\
14\end{array}$ & & 1 & $\begin{array}{c}0,3- \\
3\end{array}$ & $\begin{array}{c}0.3-3 \\
\%\end{array}$ \\
\hline \multicolumn{8}{|c|}{ Physical Properties of glass powder } \\
\hline \multicolumn{3}{|c|}{ Property } & \multicolumn{5}{|c|}{ Value } \\
\hline \multicolumn{3}{|c|}{ Specific density $(\mathrm{kg} / \mathrm{l})$} & \multicolumn{5}{|c|}{2.7} \\
\hline \multicolumn{3}{|c|}{ Specific area $\left(\mathrm{cm}^{2} / \mathrm{g}\right)$} & \multicolumn{5}{|c|}{8530} \\
\hline \multicolumn{3}{|c|}{ Color } & \multicolumn{5}{|c|}{ White } \\
\hline \multicolumn{3}{|c|}{ Pozzolanic acitivity } & \multicolumn{5}{|c|}{$28,5 \mathrm{~g}\left(\mathrm{Ca}(\mathrm{OH})_{2} / \mathrm{g}(\mathrm{GP})\right.$} \\
\hline
\end{tabular}

\section{Results \& discussion}

\subsection{Physical properties}

\subsubsection{Density}

The results of tests regarding the density at hardened state are presented in table 3 below.

Table 3. Density of the different types of slag studied mortars.

\begin{tabular}{|c|c|c|c|c|}
\hline \multicolumn{2}{|c|}{ Mortars type } & \multicolumn{3}{c|}{$\begin{array}{c}\text { Density at ages 7, 14 and 28 days } \\
\left(\mathrm{g} / \mathrm{cm}^{3}\right)\end{array}$} \\
\cline { 3 - 5 } & & 7 & 14 & 28 \\
\hline \multirow{2}{*}{ Control } & MT & 2.16 & 2.17 & 2.19 \\
\hline \multirow{3}{*}{ Slag(S) } & MS5 & 2.18 & 2.19 & 2.23 \\
\cline { 2 - 5 } & MS10 & 2.19 & 2.20 & 2.20 \\
\cline { 2 - 5 } & MS15 & 2.21 & 2.20 & 2.15 \\
\hline \multirow{3}{*}{ Combined(S+GP) } & MC1 & 2.26 & 2.25 & 2.23 \\
\cline { 2 - 5 } & MC2 & 2.23 & 2.22 & 2.21 \\
\hline
\end{tabular}




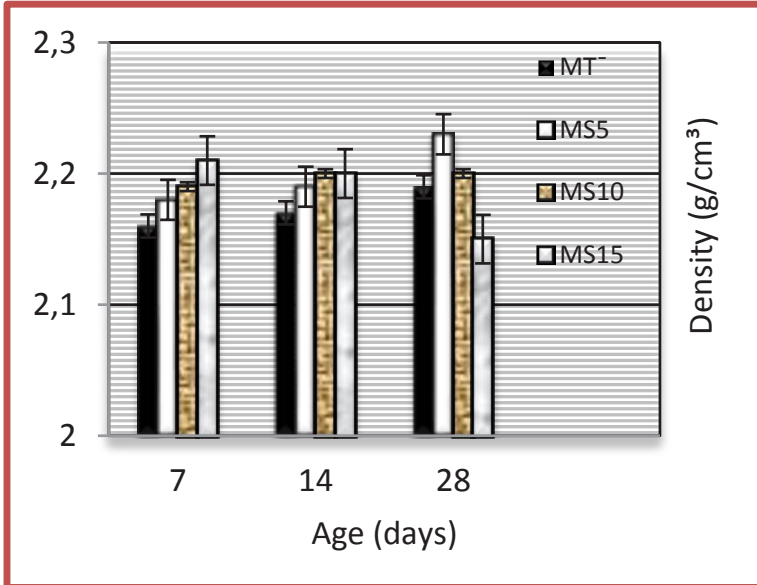

Fig 1. The variation of the density versus the age for studied slag mortars

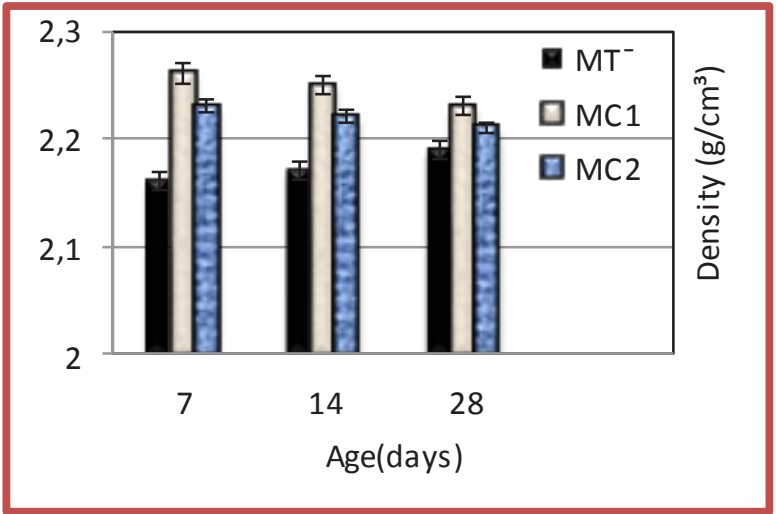

Fig 2. The variation of the density versus the age for combined studied mortars (S and GP).

According to figure 1, 2 and table 3, it can be noticed a slight increase in density in the period from 1 to 7 days for all mortar compositions and this can be explained by the need for water mortars in the first phase of hydrations. After the age of 7 days, there is a stabilization of the density because the need for water becomes lower later. Also, It can be noticed that for all the mixtures except the percentage of slag mortar, the density decreases after 28 days by comparison to the control (MT, without additions), the density is slightly greater than that of the control mortar because of the physical effect. As, this makes the cement matrix to be more dense and compact by the filling effect role played of the additions $[5,9,17]$.

This variation in density can be explained by the capacity for adsorption of water from very fine particles of additions with a higher fineness that adsorbs more water. Consequently, part of the results obtained for density increase can be attributed to this phenomenon. The density values of the mixtures are higher for the MC1 mortar compared to other studied mixtures.

\subsection{Mechanical properties}

\subsubsection{Flexural strength}

The following table 4 grouped the test results for flexural strength results.

Table 4. Flexural strength results of studied mixtures.

\begin{tabular}{|c|c|c|c|c|}
\hline \multirow{2}{*}{\multicolumn{2}{|c|}{ Mortars type }} & \multicolumn{3}{|c|}{$\begin{array}{l}\text { Flexural strength at } 7,14 \text { and } \\
28 \text { days } \\
(\mathrm{MPa})\end{array}$} \\
\hline & & 7 & 14 & 28 \\
\hline Control & MT & 4.26 & 4.41 & 4.52 \\
\hline \multirow[t]{3}{*}{ Slag(S) } & MS5 & 3.85 & 6.28 & 6.82 \\
\hline & MS10 & 4.47 & 6.32 & 7.37 \\
\hline & MS15 & 5.07 & 6.32 & 5.085 \\
\hline \multirow{2}{*}{$\begin{array}{c}\text { Combined } \\
(\mathrm{S}+\mathrm{GP})\end{array}$} & $\mathrm{MC1}$ & 6.13 & 6.93 & 7.44 \\
\hline & $\mathrm{MC} 2$ & 6.11 & 6.54 & 6.73 \\
\hline
\end{tabular}

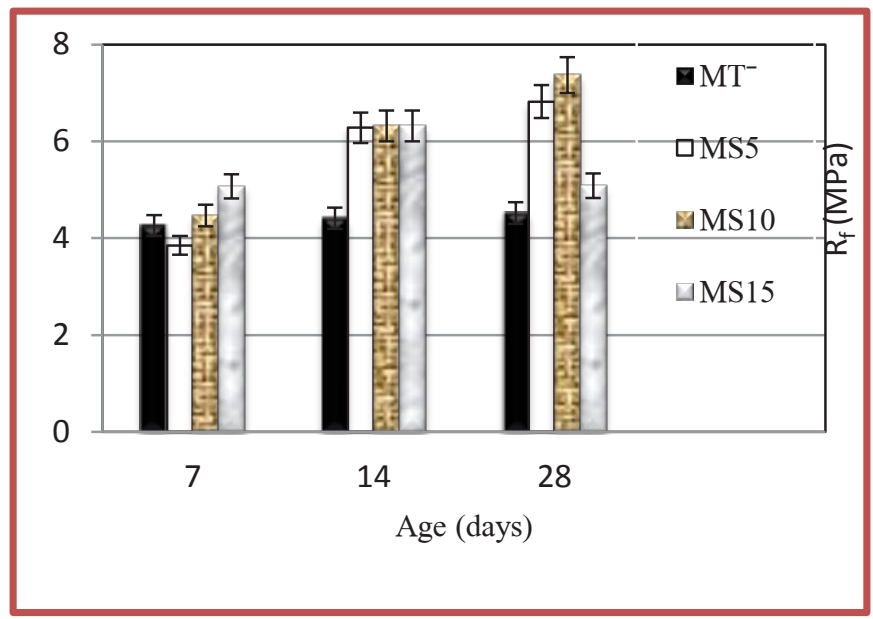

Fig 3. The variation of the flexural strength versus the age for slag studied mortars.

It can be observed from figures 3, 4 and table 4 that the results of the mechanical resistance to bending, shows a normal development trend with the age, this according to the percentage rate of (slag; glass powder) for all mortars confected with additions and the witness control one (MT), without addition. However, the flexural strengths values are better for mortars with addition regardless of the type compared to the control mixture (MT). However, the flexural strengths values are better for mortars with addition regardless of the type compared to the control mixture (MT).,

The trend towards a maximum value of mechanical resistance to bending is confirmed for the composite prepared from slag (MS10) with $7.37 \mathrm{MPa}$ compared to all mortars with slag or the witness at a value of 4.52 $\mathrm{MPa}$. Again, the increase of $\mathrm{Rf}$ is registered for combined mortars (S\&GP) up to a maximum value equal to $7.44 \mathrm{MPa}$ for $\mathrm{MCl} 1$ at $10 \%$ replacement rate.

That shows the advantageous contribution of the combination for this optimal percentage of $10 \%((5 \%$ Slag and $5 \%$ Glass Powder) and reflects an effect of pozzolanic activity role for such additives. 


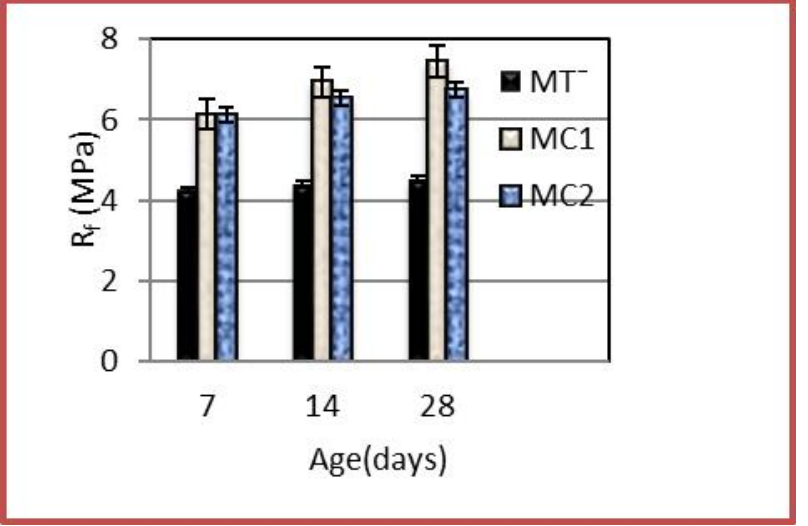

Fig 4. Variation of the flexural strength versus the age for combined mortars (S and GP).

Previous research works in the literature on the use of these additions for cementitious materials based on slag and glass powder reported the advantageous role regarding the Improvement of mechanical responses [17, $18,19,20]$.

\subsubsection{Compressive strength $\left(R_{c}\right)$}

The results of compressive strength are reported in table.6:

Table 5. Compressive strength (Rc) for studied mixtures..

\begin{tabular}{|c|c|c|c|c|}
\hline \multirow{2}{*}{\multicolumn{2}{|c|}{ Mortars type }} & \multicolumn{3}{|c|}{$\begin{array}{c}\text { Compressive strength }(\mathrm{Rc}) \text { at } 7,14 \text { and } \\
28 \text { days } \\
(\mathrm{MPa})\end{array}$} \\
\hline & & 7 & 14 & 28 \\
\hline Control & MT & 17.48 & 24.99 & 31.35 \\
\hline \multirow[t]{3}{*}{ Slag (S) } & MS5 & 37.45 & 30.77 & 52.41 \\
\hline & MS10 & 29.68 & 37.78 & 58.77 \\
\hline & MS15 & 31.61 & 36.61 & 40.34 \\
\hline \multirow{2}{*}{$\begin{array}{l}\text { Combined } \\
(\mathrm{S}+\mathrm{GP})\end{array}$} & MC1 & 34.23 & 51.18 & 52.17 \\
\hline & $\mathrm{MC} 2$ & 37.55 & 41.34 & 47.93 \\
\hline
\end{tabular}

It can be noticed from figure 5, 6 and table 5 that the mortars containing $10 \%$ slag give higher compressive strengths compared to the control mortar (58.77 MPa) and $30 \mathrm{MPa}$, respectively.

The mechanical compressive strengths increase with the age of the composite in a growing manner regardless of the rate of additions (slag or glass powder). The results obtained show in a practical way that the increase in the content of additions (slag; glass powder) leads to a greater mechanical responses. This can be explained by the fact that the chemical components of these additions directly and positively influence the speed of the hydration mechanism. This contributes to the formation of new hydrated products which increases the mechanical response by enhancement of the strength development of the cement matrix with mineral addition incorporation $[17,18,19,20]$.

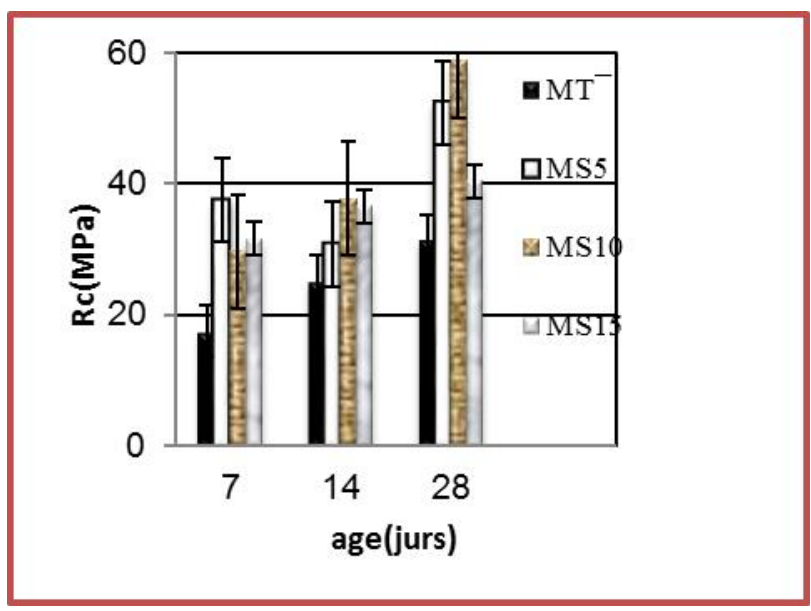

Fig 5. The variation of the compressive strength versus the age for mortars with slag.

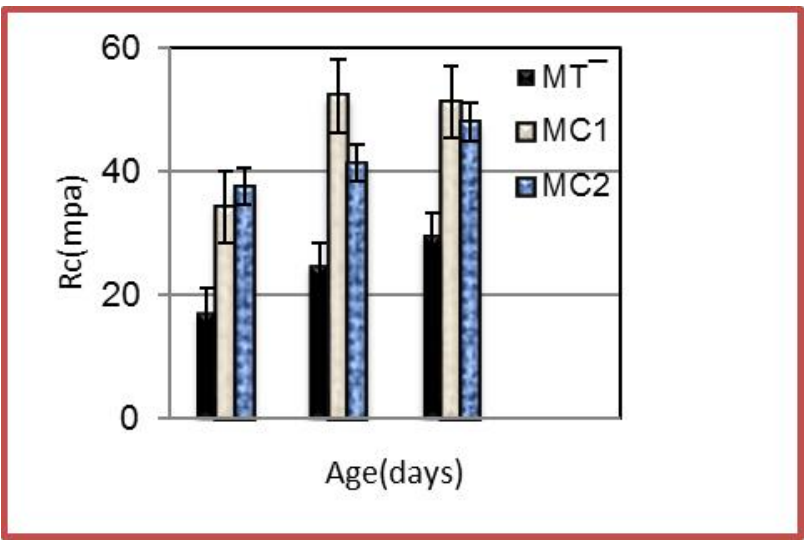

Fig 6. Variation of the compressive strength versus the age for combined mortars (S and GP).

It turns out therefore from what we have just seen that the best amount of hydrates formed could be recorded for an optimal slag content equal to $10 \%$.

For combined mortars the strengths are very important once compared to the control with a acceptable mechanical performance reaching a higher values of 47 . 97, 52;17 MPa for the dosage of $10 \%, 15 \%$ (S and GP) compared to the control mix with a lower value of 29.69 $\mathrm{MPa}$.

Glass powder, like other conventional cement additions, changes the kinetics of development of the compressive strength of mortars. Thus, it leads to a slow development of resistance, than that of controls without GP. This observation can be explained by the modifications of the hydration of the matrix induced by the substitution of cement by GP which absorbs less water than OPC cement alone [19, 20]. 


\section{Conclusion}

This experimental work is a contribution to the improvement of the properties of mortars by partial substitution of the prepared sand standardized by the mineral addition, we used two types of additions (slag and glass powder) with different rates of $5 \%, 10 \%$ and $15 \%$ for the slag alone and combined in the case (slag + glass powder (GP) up to the dosage of $15 \%$. The results obtained in this experimental study allow us to draw the following conclusions,

The incorporation of inert (glass powder) and active (slag) mineral additions to the prepared standard sand contributes positively to the improvement of mechanical performance and the density of prepared sand based mortars, at the different combinations slag alone or slag and glass powder. They allow an improvement in the compressive and flexural strengths of the mortars which are greater than that of the control mortar in the short and long term.

The introduction of up to $15 \%$ of slag has a marked effect on the resistance to compression as a function of time compared to that of the control reaching an increase more than $50 \%$ for the percentage of 10 slag replacement.

The combined introduction of $10 \%$ (slag. 5\% GP, 5\% slag), also allows the mortar to develop a tensile strength by bending and compressive resistance close to that of the control mortar at young ages ( 3 and 7 days) and with better positive mechanical performances at medium and long term improvement exceeding $40 \%$ for the optimal dosage of $10 \%$ again.

Finally, it could be concluded that the replacement of the fine fraction of 0.08 to $0.16 \mathrm{~mm}$ of prepared sand by these two additions pozzolanic slag and inert glass powder is much more advantageous and gives good physical properties and higher mechanical performances for the prepared sand based mortars.

\section{Acknowledgements}

The authors would like to thank the laboratory technical staff of the civil engineering department of M'sila university for the help given across the experimental program.

\section{References}

1. G. Dreux, J. Festa, Nouveau 7 édition, paris, 317 (1995)

2. Neville, AM, Addison-Wesley Longman Scientific and technical, UK, 3rd edtion, 779 (1981).

3. J. Provis, J.S.J Van Deventer, Woodhed Publishing Limited and CRC Press LLC, (2009)

4. N. Sedira, J.C. Gomes, Gediminas Kastiukas, Xiangming Zhou, V. Alexandre, Mineral. Chem. Character., M S, 24, 29 (2017)

5. A., Fernandez-Jimenez, J.G, Palomo, F. Puertas, Cem and Con Res, 29, 1313 (1999).
6. A. Kerbouche, M. Mouli, L. Laoufi, Y. Senhadji, S. Benosmane, Developing Countries, ENSET Oran, Algeria, 431, (2009)

7. O. Burciaga-Diaz, M.R. Díaz-Guillén, A.F Fuentes, J.I Escalante-Garcia, Const Build. Mater., 44, 607 (2013).

8. H.T. Türker,, M. Balçikanli, M., I.H Durmus, E. Özbaya, E. Mustafa, Const and Buil Mat, 104, 169 (2016).

9. A. Noui, PhD Thesis. Université de M'sila, Algérie, (2018).

10. S. Alonso \& A. Palomo, A., Mater. Letters, Roč. 47, (2001).

11. M. Lizcano, H.S Kim, S. Basu, \& M. Radovic, J. Mater. Sci, 47, 2607 (2011).

12. C. Chen, W. Gong, W Lutze, I.L. Pegg, J. Zhai, J. Mater. Sci, 46, 590 (2010).

13. M. Criado, A. Fernández-Jiménez, A. Palomo, Fuel, 89, 3185, (2010).

14. Normes européenne, Indice de classement: P15471-1, (2006).

15. EN 197-1, Ciment - Partie 1 : composition, spécifications et critères de conformité des ciments courants, (2001)

16. R. Dupain., R. Lanchon. et G.C. Saint-Arroman, Granulats, sols, ciments (1995)

17. R. Derabla, Propriétés physico - mécaniques des mortiers et des ciments élaborés à base de laitier granulé d'El Hadjar (2002).

18. W. Deboucha, M.N. Oudjit, A. Bouzid, L. Belagraa, MATBUD'2015, Cracow, Poland, (2015)

19. .B. Arab, R Mehadeden, Y. Bouchnab, Algeria (2017).

20. M Chabi, B. Lamali, Contrôle qualité des matériaux, (2017). 